
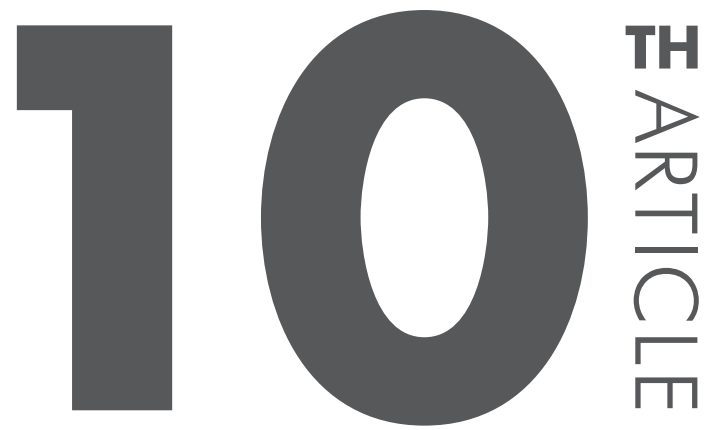

\title{
All Volatile Treatment - AVT(O) for HRSGs - Araucaria Power Station
}

Luciane Faustino, Marcos de Freitas, Fernando C. de Albuquerque

Copel - Companhia Paranaense de Energia, Araucária-PR, Brazil.

\section{ABSTRACT}

Araucaria Power Station is a $484 \mathrm{MW}$ CCGT powered by two Siemens 501FD2 gas turbines and one Alstom DKZ2-2N34 steam turbine. Two Aalborg heat recovery steam generators (HRSGs) produce $230 \mathrm{t} /$ hour of steam at $\mathrm{HP}=$ 106 barg and LP $=6,5$ barg. Araucaria Power Station is located in the southern region of Curitiba, capital of Paraná State, Brazil. Its COD (commercial Operation Date) was in September, 2002, but after 4 years laid up the plant was recommissioned in 2006 [1]. During the first years of operation, the coordinated phosphate method was adopted for boilers water treatment, as recommended by the HRSGs OEM and in accordance with the program designed by the chemicals supplier, GE Water \& Process Technologies. The coordinated phosphate method was to that point the most reliable and best known method [2]. Over the years the need for changing the boilers water treatment was observed, mainly due phosphate carryover at lower pressure operation and the risk of flow accelerated corrosion (FAC). By late 2008, HRST Inc. was contracted to design a new chemistry program for 
the plant [3]. This article compares the coordinated phosphate method to AVT(O) as applied to the plant HRSGs water treatment. It includes the results obtained with the $\operatorname{AVT}(\mathrm{O})$ after 2,936 EOH in HRSG-1 and 2,707 EOH in HRSG-2 of continuous operation.

Keywords: Power Plants, All Volatile Treatment, Combined Cycle, HRSG.

e-mail of authors: luciane.faustino@copel.com; marcos.freitas@copel.com; fernando.albuquerque@copel.com

\section{INTRODUCTION}

To maintain HRSGs reliability and availability it is necessary to prevent metal corrosion in gas and water sides. The main damaging agents are: dissolved oxygen, high temperatures, acidity or causticity. Any of them, if not controlled, can easily damage boilers in short time [2]. The choice of for water treatment in HRSGs depends on the operational characteristics of each equipment and individual reviews should be conducted before any change in method. It is also important to take in account the final application when designing boiler water treatment, either by transferring energy to a steam turbine or steam for production processes. [2] Chosen chemical treatment to prevent HRSGs damage has to provide the formation of a protective layer of magnetite. The higher the pressure of the system, the more restrictive shall be water quality control parameters. Coordinated phosphate method is the choice for most of the HRSGs in Brazil. However, recent literature shows that the flow accelerated corrosion is associated with the use of some chemicals, in particular oxygen scavengers, and they tend to take place in low-pressure circuits [3]. The use of all volatile treatment oxidizing - $\operatorname{AVT}(\mathrm{O})$ is simple and can be easily controlled by checking conductivity, after the use of oxygen scavenger is interrupted. During the operation of the plant it was observed phosphate carryover to superheaters and reduced thickness of metal in the evaporator low pressure downcomer. That prompted the change of chemical treatment and the chemicals use reduction, along with a decrease in conductivity values.

\section{DEVELOPMENT}

\subsection{Corrosion control}

Water and steam at high temperature in the HRSGs $\left(392^{\circ} \mathrm{F}\right.$ to $\left.950^{\circ} \mathrm{F}\right)$ favor the ocurrence of corrosion. As oxygen is not normally present in the system, the fundamental reaction of corrosion inside a HRSG in operation is:

$$
\begin{aligned}
& 3 \mathrm{Fe}+4 \mathrm{H}_{2} \mathrm{O} \rightarrow \mathrm{Fe}_{3} \mathrm{O}_{4}+4 \mathrm{H}_{2} \\
& \text { Iron + Water/Steam } \rightarrow \text { Magnetite + Hydrogen [3] }
\end{aligned}
$$


Magnetite layer once developed on steel surface is very durable and acts as a protective agent, preventing the direct contact of water with metal surface. Thus, the formation of an initial layer of oxide is stimulated and it functions as a corrosion inhibitor. When the magnetite layer reaches a thickness between 0.005 and $0.018 \mathrm{~mm}$, harmful corrosion is halted. Once formed, there is a minimum corrosion formation that repairs continuously the magnetite layer [3].

Low $\mathrm{pH}$ should be avoided in a boiler due to accelerated corrosion process, as the medium becomes aggressive and magnetite protective layer is harmed by acid. Make-up water too acidic or too caustic during operation also causes severe corrosion and should be avoided. Chemicals concentration in boiler water in a localized area can cause excessive levels of caustic and rapid dissolution of magnetite protective [3].

\subsection{Chemical treatment of boiler through the coordinated phosphate}

The treatment called coordinated phosphate is based on a mixture of sodium phosphates (mono-, di- and trisodium) injected into the high-pressure drum for fine $\mathrm{pH}$ adjustment. Dosage of amine and oxygen scavenger for water supply initial conditioning is also part of this method in a complementary way [4].

The type of feed water determines the type of phosphate mixture used and the proportion of each one in the mixture. Phosphate is injected in highpressure drum and their concentration depends on the pressure and desired $\mathrm{pH}$. To control the system, a phosphate vs. $\mathrm{pH}$ diagram can be used which provides coordinated guidance to the required mix to be used, as depicted in Figure 1.

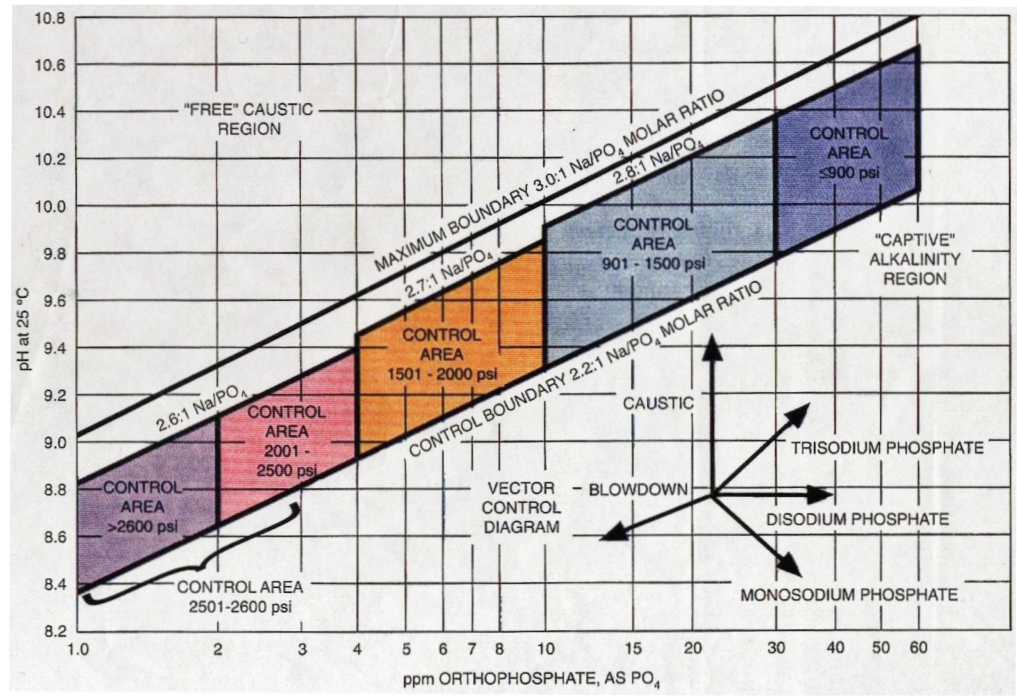

Figure 1 - Diagram of coordinated phosphate control vs. pH [4]. 
The goal is to maintain the $\mathrm{pH}$ and phosphate residual in the center of its box, taking into account the working pressure of the boiler. In cogeneration plants that use part of the steam for process, large and abrupt changes of system control parameters are common, in part due to the large volume of replacement water but also due to possible contamination of the condensate. In this case, it may be necessary to vary not only the concentration of residual phosphate in the drum, but also the proportion of phosphates in the mixture. In boiler circuits with condensate return close to $100 \%$, the system is very stable and normally the operator needs only to control the concentration of phosphate in the drum [4].

\subsection{All volatile treatment oxidizing - AVT(O) in HRSGs}

$\operatorname{AVT}(\mathrm{O})$ is a chemical treatment used in HRSGs characterized for all chemicals used tend to change from liquid into gaseous state. Dissolved oxygen in water can be removed both by mechanical action or chemical action (oxygen scavenger). Chemical scavenger residual reacts with free iron assuming a crystalline structure called Lepidocrite designated as $\mathrm{FeOOH}$, which shows color magenta. This crystal is divided in fine shape and occupies the empty spaces in surface layer of magnetite, limiting the contact of water with the base metal [3]. The presence of copper components in the steam cycle can be a limiting factor for $\operatorname{AVT}(\mathrm{O})$, but it is the preferential program for ferrous tubing HRSGs. The system $\mathrm{pH}$ is controlled only with the use of ammonia or other amine-based products, so HRSG $\mathrm{pH}$ becomes slightly lower than the rest of the system. The problem in this control scheme is that online monitoring instrumentation must function perfectly in order to ensure reliable system operation. It happens that online $\mathrm{pH}$ measurement is not always reliable. Meters commonly present problems, especially after layup periods, requiring recalibration and often replacement of electrodes. Therefore systems conditioned with ammonia are often controlled through specific conductivity, since its on-line measurement is more stable because it has a direct relation to ammonia concentration measured with the expected $\mathrm{pH}$, as shown in Figure 2. Note: It is important to note that figure 2 only considers the use of ammonia. For systems where oxygen scavenger is dosed, we must consider the scavenger interference. 


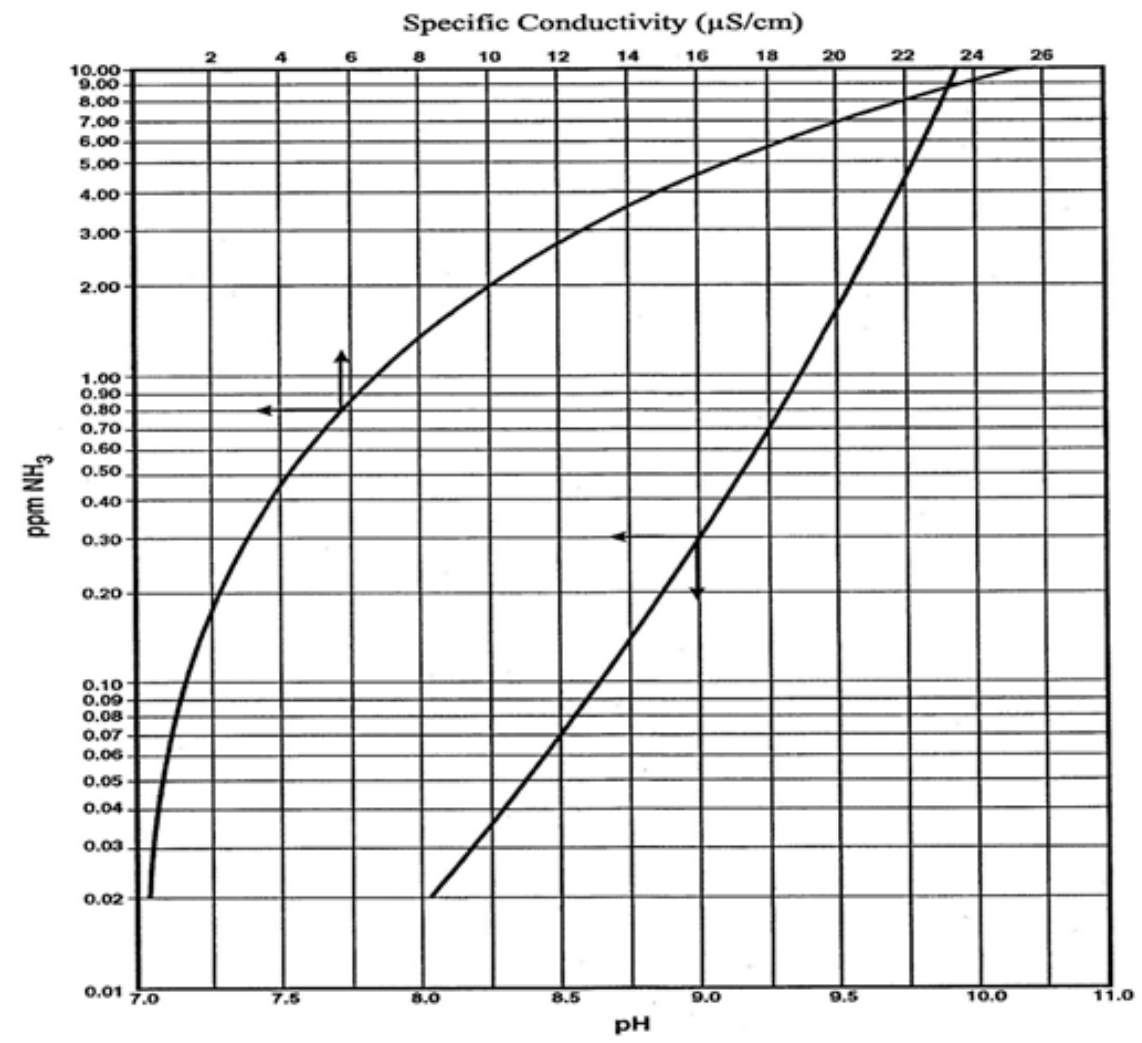

Figure 2 - Diagram of ammonia $x \times \mathrm{pH}$ conductivity at $25^{\circ} \mathrm{C}[3]$.

\subsection{Flow Accelerated Corrosion (FAC)}

FAC or flow accelerated corrosion is a corrosion mechanism that results in metal loss from pipes, fittings, vessels and other carbon steel surfaces. Studies show that it is due to the combination of certain conditions of flow, chemistry, geometry and material. FAC is often observed in HRSGs pipes in power plants. [5] FAC is a phenomenon that reduces the pressure inside the pipe when in contact with water or water-steam mixture. The risk of FAC depends on the combination of the following factors:

1. Water chemistry (promoting the dissolution of the protective film of oxide magnetite);

2. Material (steel);

3. Temperature (ranging from $200^{\circ} \mathrm{F}$ to $400^{\circ} \mathrm{F}$ ); 4 . Steam Quality (or water quality only during the phase change);

5. Shear forces (high pressure loss, high speed, or flow disturbances) [5].

In HRSGs, all economizers, evaporators, IP and LP drums are susceptible to FAC occurrence. 


\subsection{Actions taken to modify water treatment in AraucariaPower Station}

The original water chemical treatment program in Araucaria Power Station HRSGs consisted in the use of three products:

a) Basic solution of ammonium hydroxide, which aims to raise $\mathrm{pH}$ of the condensate/feed water above a minimum value of $\mathrm{pH}=8.5$, for the prevention of corrosion. Maximum value is limited to $\mathrm{pH}=9.2$ due to the presence of copper in the condenser in the original design (later modified);

b) Oxygen scavenger (carbohydrazides), used to reduce the oxygen dissolved in the condensate/feed water;

c) Phosphate (non-volatile mix of disodium and trisodium phosphates), injected into the HP drum to increase and stabilize $\mathrm{pH}$. The addition of phosphate provides the ability to tolerate high levels of contamination, finding no potentially corrosive conditions. Figures 3 and 4 shows the internal aspect of the drums, high pressure and low pressure respectively, under coordinated phosphate treatment.

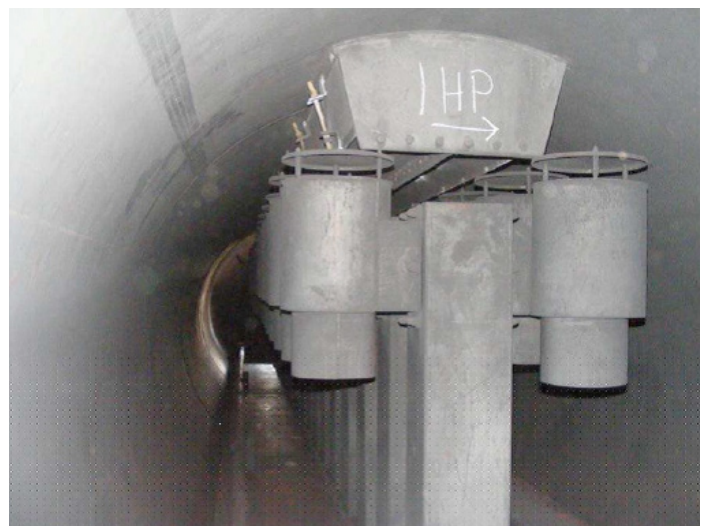

Figure 3 - HP drum under coordinated phosphate treatment.

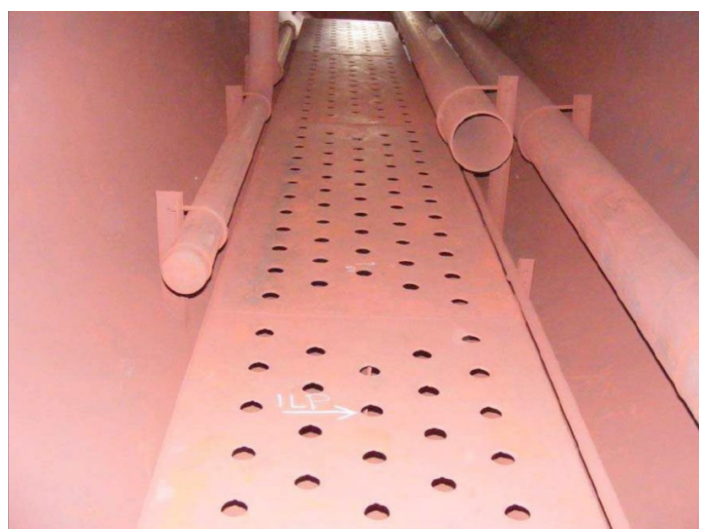

Figure 4 - LP drum under coordinated phosphate treatment. 
Because of possible phosphate carryover to the HP superheater tubes, and the looming possibility of FAC in the LP evaporator, COPEL contracted HRST Inc consulting. Based on the methodology advocated by EPRI (Electric Power Research Institute), HRST consultant recommended amending the method of chemical control system for $\operatorname{AVT}(\mathrm{O})[3]$.

The operation team implemented this new method in 2010 based on the following modifications:

a) Ammonium hydroxide, $\mathrm{pH}$ controller of the whole system. System $\mathrm{pH}$ for steam and condensate became respectively 9.3 to 9.8. At HP drum, the expected $\mathrm{pH}$ range is 9.2 to 9.6 . As there is no copper tube in the system, no restrictions for the upper $\mathrm{pH}$. This product can be injected into the feeding water pipe or into the HP drums;

b) Carbohydrazides, oxygen scavenger with chemical formula N2H3-CO-N2H3. When it reacts with oxygen it results $\mathrm{CO} 2$, which ends up dissolved in water, forming carbonic acid (H2CO3). Carbonic acid then reacts with water to form bicarbonate anions. At the end of these reactions it occurs the rise of cation conductivity. Metal surface assumes a crystalline magnetite characteristic (Fe3O4). This layer of magnetite is hard, but porous in molecular level. Water invades pores so turbulent that breaks the protective layer, contributing for FAC. Carbohydrazide use was discontinued even in startups or in wet layups, since its efficiency is very low in temperatures below $300^{\circ} \mathrm{F}$ and the harm caused by the alternation between presence and absence are much higher compared to dissolved oxygen in startup process. During the last inspection of HRSG-2, material thickness reduction was identified in the LP downcomer evaporator, as shown in Figure 5. There were suspicions of FAC initiation and the discontinuity in the use of oxygen scavenger was recommended.

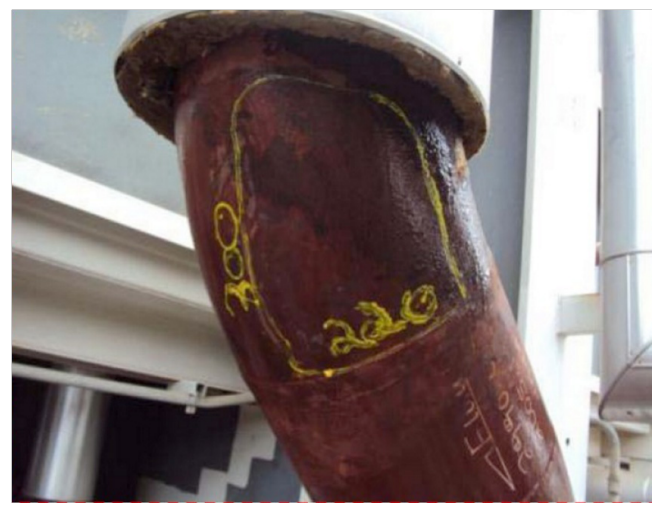

Figure 5 - Thickness loss in the LP evaporator downcomer due to FAC.

c) Phosphate, $1 \mathrm{x} 1$ operation mode significantly reduces the operating pressure in the HP drum. The transition curve provided by Aalborg demonstrates that 
the maximum steam flow is $300,000 \mathrm{lb} / \mathrm{hr}$ at $725 \mathrm{psig}$. However, the HRSG steam production reaches $500,000 \mathrm{lb} / \mathrm{hr}$. In this conditions it occurs carryover of phosphate and other solids as shown in Figure 6. Carryover deposit was detected in the primary HRSG-2 superheater lower parts, as shown in Figure 7 , and the use of phosphate is discontinued.

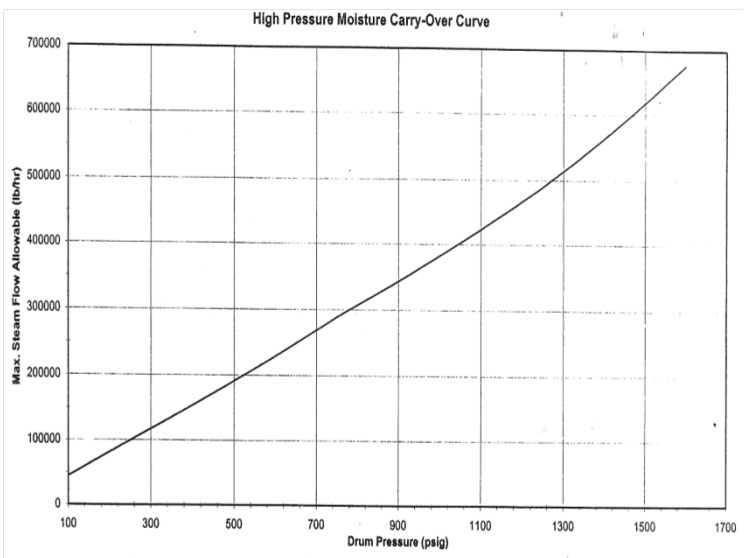

Figure 6 - Araucaria Power Station HRSGs' carryover curve.

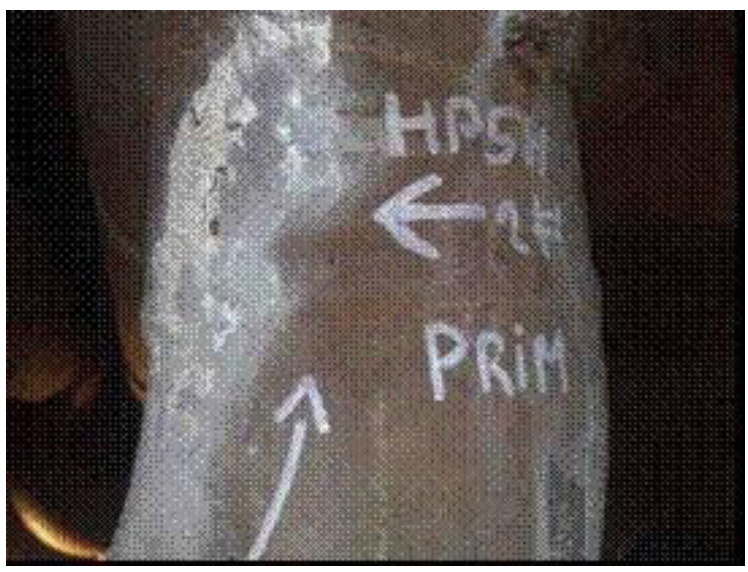

Figura 7 - Phosphate presence observed during the outage to fix HRSG-2 primary superheater leaking.

Operation at lower pressures favor the volatilization of ammonia vapor, and in transient water conditions $\mathrm{pH}$ can be as low as 9.0. To address this problem, continuous ammonia injection is done directly and exclusively in the HP drum. This dosage is sufficient to maintain satisfactory chemical parameters. Along with $\operatorname{AVT}(\mathrm{O})$, it is now in use the $\mathrm{pH}$ correction as function of ammonia directly on online instrumentation. It resulted a significant reduction in the dosage of ammonia, demonstrated by the values of cationic conductivity and cationic degassed conductivity which stabilized within the limits of the 0,20 mS. HP and LP drum 
internals appearance showed immediate changes after changing the treatment methodology, as shown in Figure 8 and 9.

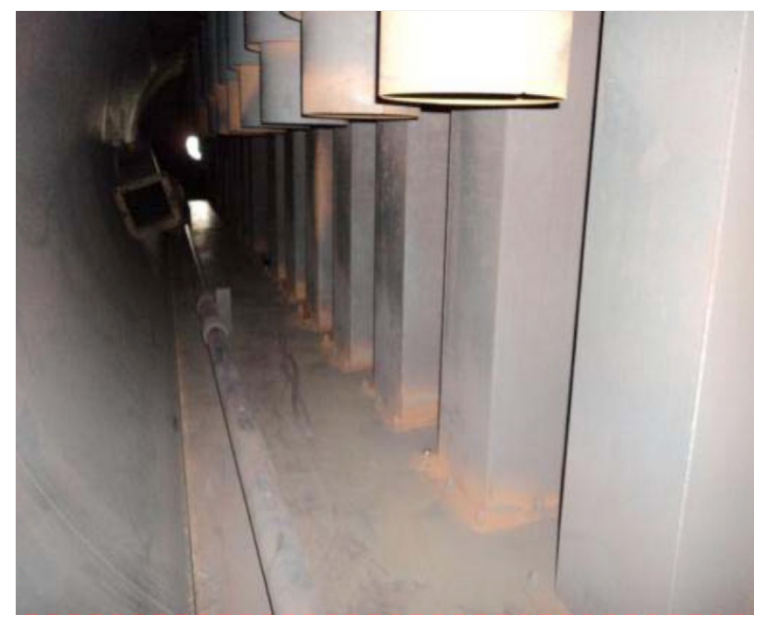

Figure 8 - HP drum under AVT(0).

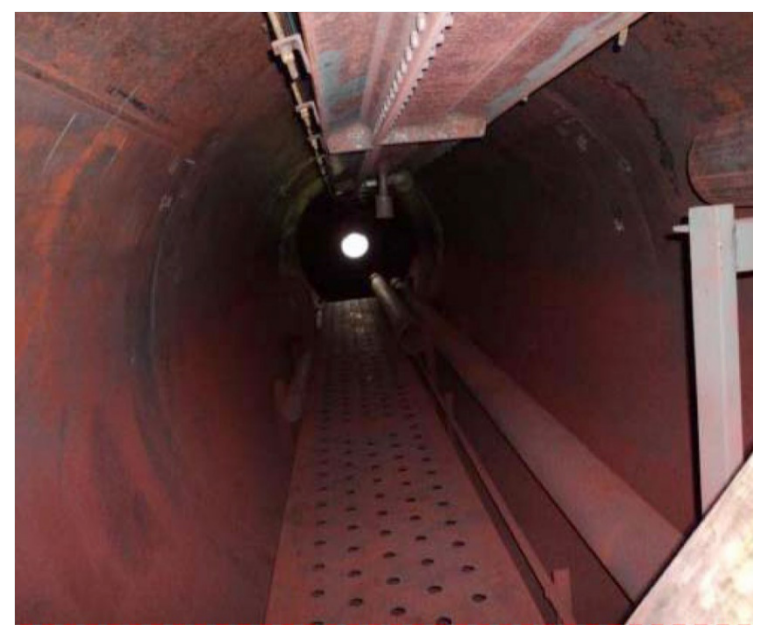

Figure 9 - LP drum under AVT(0).

On July 30, 2010 Araucaria Power Station comes into operation with $\operatorname{AVT}(\mathrm{O})$ in use. Operated until December 17, 2010, the results obtained are presented below in section 2.6 of this article.

\subsection{Results obtained}

Tables 1 and 2 show the results obtained during continuous operation of Araucaria Power Station HRSGs operation with AVT(O) method. These data are compared with coordinated phosphate results obtained in 2009. 


\section{CONCLUSIONS}

The following points resulted from the change to $\operatorname{AVT}(\mathrm{O})$ :

a) Significant reduction of specific conductivity;

b) Better control of the cation conductivity and degassed cation, which sets the work limits;

c) $\mathrm{pH}$ stable during the operation, and within limits, especially in HP drums, even using only volatile product;

d) Increased stability of the system, reducing the dosage of chemicals.

e) Reduction of the volume of chemicals used, because the oxygen scavenger and phosphate were removed from the process. Ammonia injection volume was reduced following the activation of the correction function of the conductivity temperature on the sample panel.

\section{Table 1 - HRSG-1 data}

\begin{tabular}{|c|c|c|c|}
\hline \multicolumn{4}{|c|}{ HRSC 1} \\
\hline & & $\operatorname{AVT}(0)$ & PHOSPHATE \\
\hline CTGI - Lo & $d(M W h)$ & 151.54 & 151.20 \\
\hline \multicolumn{4}{|c|}{ SP-7 CONDENSATE PUMP DISCHARGE } \\
\hline $\mathrm{pH}$ & $9,3-9,8$ & 9.88 & 9.90 \\
\hline Specific conductivity & $5-20 \mu \mathrm{S} / \mathrm{cm}$ & 15.03 & 26.05 \\
\hline Cation Conductivity & $<0,5 \mathrm{microS} / \mathrm{cm}$ & 0.30 & 0.98 \\
\hline Silica & $<10$ PPB Si02 & 11.26 & 13.60 \\
\hline Dissolved Oxygen & $<10$ PPB 02 & 2.44 & 15.74 \\
\hline Total Iron & $<9$ PPB Fe & 11.75 & 13.26 \\
\hline \multicolumn{4}{|c|}{ CONDENSATE FEEDWATER (After chemical injection) } \\
\hline $\mathrm{pH}$ & $9,3-9,8$ & 9.88 & 9.70 \\
\hline Specific conductivity & $5-20 \mu \mathrm{S} / \mathrm{cm}$ & 15.08 & 25.57 \\
\hline Oxygen Scavenger & PPB & 0 & 29.89 \\
\hline Silica & $<10$ PPB Si02 & 11.02 & 11.11 \\
\hline Total Iron & $<9$ PPB Fe & 15.78 & 43.80 \\
\hline \multicolumn{4}{|c|}{ SP-6 HRSG1 - FEEDWATER PUMP - SUCTION } \\
\hline $\mathrm{pH}$ & $9,3-9,8$ & 9.72 & 9.73 \\
\hline Specific Conductivity & $5-20 \mu \mathrm{S} / \mathrm{cm}$ & 10.38 & 17.97 \\
\hline Cation Conductivity & $<0,2 \mu \mathrm{S} / \mathrm{cm}$ & 0.19 & 0.48 \\
\hline Silica & $<10$ PPB Si02 & 7.67 & 8.19 \\
\hline Total Iron & $<9 \mathrm{PPB} \mathrm{Fe}$ & 11.35 & 76.06 \\
\hline Dissolved Oxygen & $<10$ PPB 02 & 2.75 & 6.84 \\
\hline \multicolumn{4}{|c|}{ SP-1 HRSG1 - HP DRUM } \\
\hline $\mathrm{pH}$ & $9,2-9,6$ & 9.38 & 9.39 \\
\hline Specific conductivity & $4-15 \mu \mathrm{S} / \mathrm{cm}$ & 5.98 & 10.48 \\
\hline Silica & $<1000$ PPB SiO2 & 84.85 & 111.16 \\
\hline Total Iron & $<100$ PPB Fe & 16.29 & 45.91 \\
\hline
\end{tabular}

\begin{tabular}{|c|c|c|c|}
\hline \multicolumn{4}{|c|}{ SP-2 HRSGI - HP SUPERHEATED STEAM } \\
\hline $\mathrm{pH}$ & $9,2-9,8$ & 9.70 & 9.69 \\
\hline Specific conductivity & $4-20 \mu \mathrm{S} / \mathrm{cm}$ & 10.61 & 18.13 \\
\hline Cation Conductivity & $<0,2 \mu \mathrm{S} / \mathrm{cm}$ & 0.22 & 0.87 \\
\hline Silica & $<10$ PPB Si02 & 6.37 & 5.87 \\
\hline Total Iron & $<9 \mathrm{PPB} \mathrm{Fe}$ & 9.04 & 10.53 \\
\hline Sodium & $<3$ PPB Na & 0.17 & 0.29 \\
\hline \multicolumn{4}{|c|}{ SP-5 HRSG1 - HP SATURATED STEAM } \\
\hline $\mathrm{pH}$ & $9,2-9,8$ & 9.69 & 9.69 \\
\hline Specific conductivity & $\mu \mathrm{S} / \mathrm{cm}$ & 10.65 & 18.26 \\
\hline Silica & $<10$ PPB Si02 & 6.51 & 5.62 \\
\hline Total Iron & $<9$ PPB Fe & 9.69 & 9.88 \\
\hline \multicolumn{4}{|c|}{ SP-3 HRSG1 - LP SUPERHEATED STEAM } \\
\hline Cation Conductivity & $0,8 \mu \mathrm{S} / \mathrm{cm}$ & 0.58 & 3.41 \\
\hline \multicolumn{4}{|c|}{ DEMINERALIZED WATER } \\
\hline $\mathrm{pH}$ & $6,5-8,5$ & 6.36 & 6.55 \\
\hline Specific conductivity & $<1,5 \mu \mathrm{S} / \mathrm{cm}$ & 0.88 & 0.82 \\
\hline Silica & $<10$ PPB Si02 & 5.83 & 4.67 \\
\hline Total Iron & $<9 \mathrm{PPB} \mathrm{Fe}$ & 9.23 & 9.75 \\
\hline \multicolumn{4}{|c|}{ HRSGI - KETLLE BOILER } \\
\hline $\mathrm{pH}$ & $8,9-9,3$ & 8.92 & 9.03 \\
\hline Specific conductivity & $<25 \mu \mathrm{S} / \mathrm{cm}$ & 7.00 & 14.12 \\
\hline Silica & PPB Si02 & 1091.42 & 1462.00 \\
\hline Total Iron & $<1000 \mathrm{PPB} \mathrm{Fe}$ & 525.42 & 291.79 \\
\hline
\end{tabular}




\section{Table 2 - HRSG-2 data}

\begin{tabular}{|c|c|c|c|}
\hline \multicolumn{4}{|c|}{ HRSG 2} \\
\hline & & $\operatorname{AVT}(0)$ & FOSFATO \\
\hline \multicolumn{2}{|c|}{ CTG2 - Load (MWh) } & 151.45 & 151.95 \\
\hline \multicolumn{4}{|c|}{ SP-7 CONDENSATE PUMP DISCHARGE } \\
\hline $\mathrm{pH}$ & $9,3-9,8$ & 9.88 & 9.83 \\
\hline Specific conductivity & $5-20 \mu \mathrm{S} / \mathrm{cm}$ & 14.93 & 21.94 \\
\hline Cation Conductivity & $<0,5 \mathrm{microS} / \mathrm{cm}$ & 0.31 & 0.53 \\
\hline Silica & $<10$ PPB Si02 & 11.08 & 10.22 \\
\hline Dissolved Oxygen & $<10$ PPB 02 & 2.45 & 8.80 \\
\hline Total Iron & $<9 \mathrm{PPB} \mathrm{Fe}$ & 13.03 & 15.06 \\
\hline \multicolumn{4}{|c|}{ CONDENSATE FEEDWATER (After chemical injection) } \\
\hline $\mathrm{pH}$ & $9,3-9,8$ & 9.89 & 9.66 \\
\hline Specific conductivity & $5-20 \mu \mathrm{S} / \mathrm{cm}$ & 15.00 & 21.69 \\
\hline Oxygen Scavenger & PPB & 0 & 33.74 \\
\hline Silica & $<10$ PPB Si02 & 10.74 & 9.51 \\
\hline Total Iron & $<9 \mathrm{PPB} \mathrm{Fe}$ & 16.24 & 14.77 \\
\hline \multicolumn{4}{|c|}{ SP-13 HRSG2 - FEEDWATER PUMP - SUCTION } \\
\hline $\mathrm{pH}$ & $9,3-9,8$ & 9.70 & 9.63 \\
\hline Specific conductivity & $5-20 \mu \mathrm{S} / \mathrm{cm}$ & 15.19 & 9.64 \\
\hline Cation Conductivity & $<0,2 \mu \mathrm{S} / \mathrm{cm}$ & 0.28 & 3.55 \\
\hline Silica & $<10$ PPB Si02 & 6.72 & 9.25 \\
\hline Total Iron & $<9$ PPB Fe & 11.11 & 4.94 \\
\hline Dissolved Oxygen & $<10$ PPB 02 & 2.89 & 14.95 \\
\hline \multicolumn{4}{|c|}{ SP-8 HRSG2 - HP DRUM } \\
\hline $\mathrm{pH}$ & $9,2-9,6$ & 9.36 & 9.33 \\
\hline Specific conductivity & $4-15 \mu \mathrm{S} / \mathrm{cm}$ & 5.37 & 8.93 \\
\hline Silica & $<1000$ PPB Si02 & 86.08 & 49.25 \\
\hline Total Iron & $<100$ PPB Fe & 31.78 & 10.61 \\
\hline
\end{tabular}

\begin{tabular}{|c|c|c|c|}
\hline \multicolumn{4}{|c|}{ SP-9 HRSG2 - HP SUPERHEATED STEAM } \\
\hline $\mathrm{pH}$ & $9,2-9,8$ & 9.69 & 9.61 \\
\hline Specific conductivity & $4-20 \mu \mathrm{S} / \mathrm{cm}$ & 10.49 & 15.34 \\
\hline Cation Conductivity & $<0,2 \mu \mathrm{S} / \mathrm{cm}$ & 0.20 & 0.31 \\
\hline Silica & $<10$ PPB Si02 & 6.52 & 6.92 \\
\hline Total Iron & $<9 \mathrm{PPB} \mathrm{Fe}$ & 9.72 & 10.27 \\
\hline Sodium & $<3 \mathrm{PPB} \mathrm{Na}$ & 0.30 & 0.85 \\
\hline \multicolumn{4}{|c|}{ SP-12 HRSG2 - HP SATURATED STEAM } \\
\hline $\mathrm{pH}$ & $9,2-9,8$ & 9.69 & 9.60 \\
\hline Specific conductivity & $\mu S / \mathrm{cm}$ & 10.42 & 14.99 \\
\hline Silica & $<10$ PPB SiO2 & 6.44 & 10.03 \\
\hline Total Iron & $<9$ PPB Fe & 9.98 & 11.12 \\
\hline \multicolumn{4}{|c|}{ SP-10 HRSG2 - LP SUPERHEATED STEAM } \\
\hline Cation Conductivity & $0,8 \mu \mathrm{S} / \mathrm{cm}$ & 0.41 & 4.73 \\
\hline \multicolumn{4}{|c|}{ DEMINERALIZED WATER } \\
\hline $\mathrm{pH}$ & $6,5-8,5$ & 6.36 & 7.08 \\
\hline Specific conductivity & $<1,5 \mu \mathrm{S} / \mathrm{cm}$ & 0.88 & 0.77 \\
\hline Silica & $<10$ PPB Si02 & 5.83 & 4.57 \\
\hline Total Iron & $<9$ PPB Fe & 9.27 & 9.47 \\
\hline \multicolumn{4}{|c|}{ HRSG2 - KETLLE BOILER } \\
\hline $\mathrm{pH}$ & $8,9-9,3$ & 9.01 & 8.69 \\
\hline Specific conductivity & $<25 \mu \mathrm{S} / \mathrm{cm}$ & 7.51 & 11.39 \\
\hline Silica & PPB Si02 & 916.30 & 2886.64 \\
\hline Total Iron & $<1000$ PPB Fe & 570.01 & 711.91 \\
\hline
\end{tabular}




\section{REFERENCES}

[1] FREITAS, M., ALBUQUERQUE, F.C., FERREIRA, J.C.N. Combined Cycle Power Plant Long Term Preservation Program: the Araucaria Power Station Study Case. ASME Turbo Expo 2008 and POWER-GEN International 2009.

[2] [2]Tratamento Coordenado PO4 / pH -1. GE WATER \& POWER TECHNOLOGIES, 2004.

[3] WITHERPOW, J. Chemistry Review for October 2009 - Final Report. HRST Inc, 2009.

[4] FAUSTINO, L.; SILVA, S. F. O tratamento químico do circuito água-vapor da UTE Araucária. VI ETOM. Foz do Iguaçu-PR, 2006.

[5] PAVAGEAU, E. M. Effect of Hydrazine on Flow Accelerated Corrosion. EPRI-1008208, 2005.

[6] DOOLEY, B.; SHIELDS, K. Cycle Chemistry for Conventional Fossil Plants and Combined Cycle/HRSGS. In: EPRI2004. PPChom, 2004. 